\title{
Florescimento dos Jovens na Escola
}

\section{Flourishing of Youngsters at School}

\author{
Maria Cristina Faria \\ Instituto Politécnico de Beja
}

\begin{abstract}
Resumo
A diversidade do processo de desenvolvimento que ocorre durante a Juventude remete-nos para a importância de uma abordagem psicológica na Escola, em articulação com a Família e a Comunidade. Esta intervenção permite chegar ao Jovem, assegurando a promoção de um desenvolvimento harmonioso e apoiando-o de forma especializada nas dificuldades sentidas. Martin Seligman (2011) no seu livro "Flourish" sugere uma compreensão visionária da felicidade e do bem-estar. Para florescer o indivíduo tem de possuir determinadas características e nem todos têm as competências certas para alcançar bem-estar. Fica aqui um alerta para a relevância de uma Educação Positiva na Escola que prepare os alunos para florescer e serem felizes. Neste trabalho pretendemos mostrar a importância desta intervenção psicoeducativa na Escola.

Palavras chave: jovens, escola, florescimento, psicologia positiva
\end{abstract}

\begin{abstract}
The diversity of the development process that occurs during the Youth brings us to the importance of a psychological approach in the School, in articulation with the Family and the Community. This intervention makes it possible to reach out to the Youth, ensuring the promotion of a harmonious development and supporting it in a specialized way in the difficulties experienced. Martin Seligman (2011) in the book "Flourish" arises a visionary understanding of happiness and well-being. To flourish the individual has to possess certain characteristics and not all have the right skills to achieve well-being. Here is an alert for the relevance of Positive Schooling that prepares students to flourish and be happy. In this work we intend to show the relevance of this psychoeducational intervention in the School.

Keywords: young, school, flowering, positive psychology
\end{abstract}

Os Jovens da sociedade contemporânea assistem a um ritmo acelerado de acontecimentos positivos e negativos à esfera local e global, vivem ambientes tecnológicos efémeros e são estimulados para uma vida que é consumo, isto é, que privilegia a máxima do ter momentâneo, deixando para segundo plano a tomada de consciência de saúde e a expressão do ser, do pensar, do sentir e do interagir humano com qualidade. Nesta perspetiva a felicidade parece depender em pleno da economia. Esta forma intensa de viver não permite tempo para encontrar um significado consciente da existência humana e identificar o que realmente interessa, dificultando o delinear de um projeto de vida e a visão de um futuro positivo e esperançoso. É preciso que os jovens não desperdicem o seu tempo nem o seu potencial, se queremos uma humanidade melhor. As evidências mostram que o materialismo excessivo é uma causa de infelicidade. Contudo, nem todos os jovens se deixam manipular por esta sociedade, muitos realizam opções de vida gratificantes e promissoras de êxito, porque a família, a escola e a comunidade estão atentas às novas gerações, facultando a criação de ambientes enriquecedores da vida humana e promotores de aprendizagens e desenvolvimento de competências de florescimento. Ajudar as crianças e os jovens a serem felizes tem que ser o objetivo principal dos seus pais, mas também da escola e da comunidade. É preciso saber orientar para o bem-estar e sintonizar as forças no sentido do desenvolvimento de uma inteligência emocional e de uma educação positiva que será frutuosa, quando os jovens mostrarem que são bem sucedidos e felizes. $\mathrm{Na}$ interação humana as emoções são uma constante da vida, curiosamente são contagiosas, cabendo ao indivíduo a responsabilidade de filtrar as emoções da situação e o impacto que estas podem ter na sua vida. Os princípios da inteligência emocional a que fazem referência os autores remetem-nos para competências que os indivíduos devem apresentar, tais como: (1) tomar consciência dos seus próprios sentimentos e dos sentimentos dos outros; (2) revelar empatia e compreender os pontos de vista dos outros; (3) regular e enfrentar de um modo positivo os impulsos emocionais e comportamentais; (4) ter uma orientação positiva nos seus objetivos e no seu planeamento; e (5) utilizar competências sociais positivas nos seus relacionamentos (Goleman, 2001). O desenvolvimento de competências emocionais desde a infância até à idade adulta pode fazer a diferença para alcançar uma vida saudável, feliz e com êxito, e segue-se em frente no caminho para a prosperidade na rota da felicidade.

\section{Felicidade}

Sabemos que ao longo da humanidade a felicidade é importante na vida dos humanos, contudo defini-la em termos científicos pode parecer complexo. De acordo com Martin $(2006,25)$ trata-se de um estado mental composto por três elementos que se combinam entre si: (1) Prazer (estados de espírito ou emoções agradáveis, 
como prazer, contentamento, alegria, exaltação, êxtase e afeto; (2) Ausência de desprazer (ausências de estados de espírito desagradáveis e negativas, como tristeza, ansiedade, medo, ira, culpa, inveja e vergonha); e (3) Satisfação (ajuizar que se está satisfeito com alguns aspetos da vida, como as relações pessoais, carreira ou capacidades físicas). Pode ainda ser considerado um quarto elemento, o Significado, entendido como um sentimento de que a vida deve possuir um propósito mais profundo para além do prazer ou da satisfação. De acordo com o autor os estudos mostram que as caraterísticas das pessoas felizes remetem para um registo de: (1) Conetividade; (2) Competência social e emocional; (3) Inexistência de ansiedade excessiva; (4) Habilidades de comunicação; (5) Envolvimento em atividades significativas; (6) Sensação de controlo; (7) Sentido de propósito ou significado; (8) Resiliência; (9) Auto-estima; (10) Otimismo; (11) Focalização externa; (12) Disposição para o presente e para o futuro; (13) Humor; (14) Jovialidade; (15) Sabedoria; (16) Libertação de materialismo excessivo; e (17) Estado de fluxo frequente.

Csikszentmihalyi $(2000,2002)$ dedicou o seu estudo aos estados de "experiência ótima", isto é, os estados em que uma pessoa desfruta verdadeiramente de alguma coisa ou em que se concentra ativamente numa tarefa. $\mathrm{O}$ fluxo (estado de satisfação profunda) ocorre quando um indivíduo expande os seus pontos fortes e os seus talentos no sentido de enfrentar os desafios que lhe surgem no caminho. A sensação é a de que se está imerso em felicidade e de forma significativa, no momento e na atividade (Csikszentmihalyi, 2000). De acordo com o autor da visão da psicologia da experiencia ótima, "fluir" explica como o fluxo pode ser controlado, provocado e como podemos recorrer à sua energia para enfrentar os desafios concretos da vida Assim, o fluxo estimula e facilita a aprendizagem. Como refere o autor "Os melhores momentos de nossas vidas não são os momentos passivos, recetivos $e$ relaxantes (...). Os melhores momentos costumam ocorrer se o corpo ou mente de uma pessoa estiver esticada até seus limites num esforço voluntário para conseguir algo difícil e valioso." (Csikszentmihalyi, 1990, 3). Durante a "experiência ótima" os indivíduos sentem-se "fortes, alertas, com controlo sem esforço, sem sofrimento e no auge de suas habilidades". Para Csikszentmihalyi (1990) a felicidade não acontece simplesmente, deve ser preparado e cultivada por cada pessoa, estabelecendo desafios que não são nem exigentes nem muito simples para as aptidões.

Seligman (2002) no seu livro "Authentic Happiness: Using the New Positive Psychology to Realize Your Potential for Lasting Fulfillment", traduzido para português com o título de "Felicidade Autêntica Usando a Nova Psicologia Positiva para a Realização Autêntica", ultrapassa o determinismo genético e considera que o nível de felicidade pode ser aumentado, mostrando os fatores que a influenciam, em particular, como os fatores pessoais se encontram relacionados com a felicidade, a saúde e a longevidade. Por exemplo, no campo da saúde as evidências mostram que pessoas felizes adoecem menos, vivem mais tempo, faltam menos ao trabalho e apresentam maior produtividade. Por conseguinte, o recurso às forças e virtudes pode conduzir à felicidade autêntica, proporcionando um significado e satisfação sustentável à vida. $\mathrm{O}$ bem-estar surge como fruto da integração das nossas forças e virtudes, e nesta situação a vida fica imbuída de autenticidade. No seu livro apresenta as seis principais virtudes do ser humano: (1) sabedoria e conhecimento; (2) coragem; (3) amor e humanidade; (4) justiça; (5) temperança; e (6) espiritualidade e transcendência. Cada individuo através do recurso às forças e virtudes que possui evidência o seu nível de felicidade individual. No entanto, de acordo com Seligman (2002) tudo pode ser aprendido e melhorado. Nesta perspetiva podemos preparar os humanos desde crianças para encontrar a felicidade no seu caminho. A investigação científica sugere que a felicidade está mais próxima de uma competência que pode ser adquirida do que dos genes que possuímos. Contudo, não podemos esquecer a dimensão pessoal destacada por muitos estudos, onde se realça que ser feliz altera sistematicamente o modo como percebemos o mundo. Como diz Martin " $A$ felicidade e o sucesso andam de mãos dadas. As investigações têm demonstrado que as pessoas felizes são de modo geral, mental e fisicamente mais saudáveis, mais bem-sucedidas na sala de aula e no trabalho, mais criativas, mais populares, mais sociáveis, com maior experiência de vida e com menos probabilidades de se tornarem criminosas ou toxicodependentes. Em resumo, as crianças felizes tornam-se melhores estudantes $e$ melhores trabalhadores." $(2006,19)$. Observamos que desde os primeiros tempos de vida que a felicidade contribui para o sucesso e vice-versa. Diversos estudos confirmaram que as crianças mais felizes têm melhor desempenho escolar do que as crianças mais infelizes, e salientam que as crianças que se sentem bem consigo mesmas demonstram maiores capacidades para a leitura, a ortografia e a matemática, e são avaliadas pelos professores como sendo mais populares, mais cooperantes e mais persistentes na sala de aula, isto é, "As crianças são mais resilientes e mais capacitadas para desatar os nós da vida." (Martin, 2006, 37). Pelo contrário, as crianças infelizes alcançam menos objetivos na escola e têm uma maior tendência para procurar alívio nas substâncias químicas. A infelicidade, a baixa auto-estima e a ansiedade são grandes fatores de risco para o consumo excessivo de drogas e de álcool nos jovens, tal como nos adultos. Por conseguinte, orientar emocionalmente os humanos, desde crianças a adultos, pode ser a chave da prosperidade. Desenvolver competências emocionais que levam ao crescimento de competências empreendedoras e a aprendizagens gratificantes promotoras de empreendedorismo e sustentabilidade, permitem construir personalidades com vidas saudáveis, realizadas e com êxito. É neste contexto que a Psicologia pode dar o seu contributo, na orientação dos indivíduos para a realização humana e para a proteção da sua saúde mental ao longo da vida. A atuação psicológica passará pelo desenvolvimento da inteligência emocional e por uma educação positiva que possibilite o florescimento. 


\section{Florescimento}

A Teoria da Felicidade Autêntica de Seligman (2002) afirma que as nossas escolhas estão em consonância com as estimativas de quanta felicidade (satisfação com a vida) se seguirá, realizando opções sobre o percurso de felicidade futura de forma a maximizá-la. Compreende que a felicidade pode ser dividida em três aspetos distintos escolhidos pelos seus valores intrínsecos: (1) emoção positiva (aquilo que sentimos) que contribui para uma "vida agradável"; (2) envolvimento (centra-se no fluxo) que contribui para uma "vida envolvida"; e (3) significado (pertença e serviço a algo maior do que o eu) que contribui para uma "vida com significado".

No início, o autor considerava que o tópico da Psicologia Positiva era a felicidade, que se avaliava através da satisfação com a vida e que o objetivo desta psicologia seria aumentar a satisfação com a vida. Mais tarde, Seligman (2012) no seu livro "Flourish", traduzido para português " $A$ vida que floresce" surge com uma nova compreensão da felicidade e do bem-estar e apresenta-nos como objetivo da psicologia positiva aumentar a quantidade de florescimento na vida dos humanos e do planeta. Considera que existem insuficiências na primeira conceção e propõe que o tópico da Psicologia Positiva seja o bem-estar, que o padrão de excelência para o avaliar seja o florescimento (emoção positiva, envolvimento, significado, relações positivas e realização pessoal) e que o objetivo da Psicologia Positiva seja aumentar o florescimento, promovendo a emoção positiva, o envolvimento, o significado, as relações positivas e a realização pessoal.

Na sua teoria sobre o bem-estar (The PERMA Model: $\mathrm{P}=$ Positive Emotion $; \mathrm{E}=$ Engagment $; \mathrm{R}=$ Relationships; $\mathrm{M}=$ Meaning; $\mathrm{A}=$ Accomplishments) apresenta-nos cinco elementos (emoção positiva, envolvimento, significado, relações positivas e realização pessoal) e cada um deles possui três propriedades: (1) contribuir para o bem-estar; (2) ser desejado por muitas pessoas pelo seu valor intrínseco; e (3) ser definido e medido de forma independente dos outros elementos (exclusividade). Para florescer o individuo tem de possuir todas as caraterísticas nucleares (emoções positivas; envolvimento, interesse; significado, propósito) e três das seis caraterísticas adicionais (auto-estima; otimismo; resiliência; vitalidade; autodeterminação; relações positivas). De acordo com o autor a teoria da felicidade autêntica é unidimensional, isto é, refere-se às questões relativas a sentimo-nos bem e afirma que o modo como optamos pelo nosso percurso de vida é tentando maximizar o que sentimos. Por outro lado, a teoria do bem-estar refere-se aos cinco pilares, e os alicerces dos cinco elementos são as virtudes e os pontos fortes. No seu entender “(...) o bem-estar é uma combinação entre sentirmo-nos bem e termos, de facto, significado, boas relações e realização pessoal. A forma como escolhemos o nosso percurso de vida é maximizando todos estes cinco elementos." (Seligman, 2012, 39). Diante desta panorâmica, nem todos os indivíduos têm as competências certas para alcançar bem-estar, ou então apresentam dificuldades em adquiri-las ou desenvolvê-las. Neste seguimento, surge a necessidade de uma Educação Positiva na Escola que prepare os alunos para florescer e serem felizes o mais cedo possível e ao longo da vida. Para que tal aconteça é preciso que também os professores estejam disponíveis para florescer e que com todos a escola floresça.

\section{Educação Positiva}

Quando os pais são questionados sobre o que é que eles mais desejam para os seus filhos e sobre o que efetivamente as escolas ensinam (Seligman, Ernst, Gillham, Reivich \& Linkins, 2009), referem no primeiro caso e de uma maneira geral que desejam bem-estar (felicidade, confiança, contentamento, equilíbrio, "coisas boas", bondade, saúde, satisfação) e no segundo caso consideram que a escola ensina a realização, habilidades de pensamento, sucesso, conformidade, literacia, matemática, disciplina. É ainda mencionado que poucas são as escolas que disponibilizam ferramentas para a realização. Como podemos observar à primeira vista a escola não ensina aquilo que os pais mais ambicionam para os seus filhos, ficando somente por procurar preparar as novas gerações para o mundo do trabalho dos adultos. E se a escola conseguisse ensinar habilidades de bem-estar e de realização em simultâneo? Mas será que se justifica e é possível ensinar bem-estar?

Os estudos têm mostrado uma prevalência de depressão, por sinal elevada, entre os jovens de todo o mundo. Cerca de $20 \%$ dos jovens vivenciam um episódio de depressão clínica até o final da escolaridade (Lewinsohn, Rohde, Seeley \& Fischer, 1993), verificando-se o aumento da sua incidência nos últimos anos e o seu início tende a surgir na adolescência e já nem tanto nos adultos. Se nos centrarmos no ambiente, podemos observar que vivemos num mundo moderno melhor que há 60 anos, onde existe maior poder de compra, as habitações são maiores, mais carros, estradas, e roupa, direito a férias, acesso à educação ao longo da vida, direitos das mulheres, controlo ambiental, menos racismo, menos poluição, mais música e entretenimento, acesso a livros e tecnologias, enfim, à primeira vista podemos ficar impressionados, mas, depois temos o terrorismo, os refugiados, a corrupção, a falta de segurança e a prioridade da economia. Como referem os autores, tudo é melhor exceto a moral humana (Seligman, Ernst, Gillham, Reivich \& Linkins, 2009). Assistimos ao incremento da depressão e da ansiedade e verificamos que a felicidade não acompanhou a melhoria no mundo. $\mathrm{O}$ dinamarquês médio, italiano e mexicano está um pouco mais satisfeito com a vida do que há 60 anos, mas a média americana, japonesa ou australiana não está mais satisfeita com a vida do que há 60 anos, e a média britânica ou alemã está menos satisfeita (Inglehart, Foa, Peterson \& Welzel, 2007). A depressão generalizada, os aumentos irregulares de felicidade e o facto de mais bem-estar se encontrar em sinergia com uma melhor aprendizagem, (o objectivo tradicional de educação), constituem três boas razões que justificam ensinar bem-estar. Considerando que a maioria dos jovens frequenta a escola e que é neste espaço que passa grande 
parte das suas vidas, as escolas oferecem a oportunidade de alcançar metas de bem-estar e melhorar a sua difusão em grande escala. Os estudos apresentados pelos autores sugerem que humor positivo produz mais atenção, mais pensamento criativo e mais pensamento holístico em contraste com o humor negativo que produz uma atenção mais estreita, pensamento mais crítico e mais pensamento analítico. Ambas as formas de pensar são importantes, mas as escolas enfatizam o pensamento crítico, em vez de promover o pensamento criativo. Por conseguinte, o bem-estar pode ser ensinado na escola por três motivos: (1) combater a depressão; (2) promover a satisfação com a vida; e (3) apoiar a aprendizagem e o pensamento criativo (Seligman, Ernst, Gillham, Reivich \& Linkins, 2009). De acordo com Cohen (2006; cit. Seligman, Ernst, Gillham, Reivich \& Linkins, 2009) a maioria dos pais e educadores dos nossos dias vê a promoção do bem-estar e do caráter como um aspecto importante e central da escolaridade, destacando que o objetivo primordial da educação passa por preparar as crianças e os jovens para se tornarem cidadãos responsáveis. No presente, já podemos observar que o treino do coração e da mente em contexto educacional é fundamental e começa a tomar relevo. De acordo com os autores, os programas de bem-estar desenvolvidos na escola podem: 1) promover aptidões e robustez que são valorizadas pela maioria dos pais; 2) produzir melhorias mensuráveis no bem-estar e no comportamento dos estudantes; e 3) facilitar o envolvimento dos alunos na aprendizagem e realização. Destaquemos algumas experiências orientadoras para ensinar o bem-estar na escola apresentadas por Seligman (2012): (1) Programa de Resiliência da Universidade de Pensilvânia; e (2) o Programa do Colégio de Geelong na Austrália. Relativamente ao primeiro caso, o curso decorreu durante o ano letivo, em sessões de mais de vinte e oito minutos, e os seus principais objetivos foram: "ajudar os alunos a identificar os seus pontos fortes de caráter especifico" e "aumentar a utilização desses pontos fortes na sua vida quotidiana". Mas, também, promover a resiliência, a emoção positiva, o significado e o propósito, e as relações sociais positivas. $\mathrm{O}$ curso de Psicologia Positiva de Strath Heaven contribui para melhorar os pontos fortes de curiosidade, amor pela aprendizagem e criatividade, e ainda aumentou a satisfação e o envolvimento dos jovens na escola. O programa melhorou também as competências sociais (empatia, cooperação, assertividade, autocontrole) e reduziu a má conduta. No segundo caso, tudo começou por se ensinar primeiro e em nove dias os professores do colégio a saberem usar as competências pessoais e profissionais das suas vidas e depois, eram-lhes apresentados de forma interativa os exemplos e os programas que poderiam utilizar para saberem ensinar as suas crianças. A Educação positiva viva pode ser estimulada desde cedo na escola. Podemos planear e estimular que ela aconteça e seja uma realidade constante como no caso dos alunos de seis anos da Geelong Grammar School (Seligman, Ernst, Gillham, Reivich \& Linkins, 2009, 307): "Kyle começa seu dia num semi-círculo com seus colegas de classe uniformizados e de primeiro grau.
Frente ao seu professor, a mão de Kyle disparou quando ela perguntou: "Crianças, o que correu bem ontem à noite?". Ansiosos para responder, vários alunos do primeiro ano compartilhavam anedotas breves como "Nós tivemos a minha última noite favorita - espaguete" $e$ "Eu joguei damas com meu irmão mais velho $e$ ganhei". O positivo Kyle disse: "Minha irmã e eu limpámos o pátio depois de jantar e mamã abraçou-nos depois de terminarmos. "O professor seguiu com Kyle. "Por que é importante compartilhar o que correu bem?" Ele não hesitou. "Isso faz-me sentir bem." 'Mais alguma coisa, Kyle?' 'Oh, sim, a minha mãe quando eu chego a casa, pergunta, todos os días, o que correu bem, e ela fica feliz quando eu lhe conto. E quando a mamã está feliz, todos estão felizes." De uma maneira geral podemos dizer que a educação positiva é a combinação da educação tradicional com o estudo da felicidade e do bem-estar. Utilizar a Psicologia Positiva na perspetiva do florescimento na Escola torna os alunos e os professores mais felizes, envolve-os e produz prosperidade.

\section{Envolvimento dos Alunos na Escola}

No domínio da Psicologia e da Educação, a investigação e a intervenção tem dado um particular destaque ao conceito de envolvimento dos alunos na escola, como uma alternativa aos problemas da escola e como via de desenvolvimento dos seus. Veiga, Pavlovic, García, e Ochoa (2010) referem que este conceito é apresentado como um constructo multidimensional que agrega três dimensões: afetivas, comportamentais e cognitivas de adaptação à escola. Nesta perspetiva, é preciso compreender como o aluno se encontra ligado à escola e até que ponto ele é considerado o agente da ação. Trata-se de um conceito transdisciplinar que tem sido apontado como a via de respostas aos problemas nas escolas dos nossos dias. (Veiga, 2013). Os sentimentos positivos de pertença e referência à escola encontram-se em permanente atualização e são determinados pela vivência e resultados escolares, mas, também, pelo tipo de apoio e atenção que a escola disponibiliza a cada um dos seus alunos. Do pré-escolar ao ensino superior e à formação ao longo da vida para além de envolver é preciso capacitar os alunos ao nível do seu desenvolvimento pessoal e social. Este é um desafio que qualquer nível de ensino não pode descuidar se quiser construir cidadãos responsáveis e futuros profissionais competentes e felizes. A escola para além de dotar os seus alunos de um saber cognitivo e de os envolver, deve promover iniciativas pedagógicas que permitam aos seus alunos serem detentores de um saber ser e sentir e capazes de comunicar assertivamente e de expressar afetos. A Escola não pode descuidar a missão de capacitar e apoiar os seus alunos no desenvolvimento das suas aptidões e na superação das suas dificuldades; proporcionando abordagens inovadoras e ambientes enriquecedores, que possibilitem aprendizagens, interações e experiências significativas de vida, que orientem o pensamento e a ação para a realização do projeto de vida de cada estudante com êxito. 


\section{Discussão}

Seligman (2002, 2011) quando abraçou a Psicologia Positiva considerou que seria relevante fazer uma opção e passar de uma atuação em que o foco principal era remover as condições debilitantes, para uma abordagem de criar as condições propícias para as pessoas florescerem. A Psicologia Positiva aplicada ao contexto escolar evidencia como determinadas forças de caráter são oportunidades de crescimento para os alunos permitindo-lhes alcançar o seu pleno potencial. Os estudos mostram que o otimismo e o pessimismo desempenham um papel importante na adaptação à escola. Os alunos otimistas tendem a enfrentar com êxito os desafios que a escola lhes coloca, já os alunos pessimistas apresentam mais hostilidade em relação à escola e formas destrutivas de lidar com a irritabilidade (Boman, Smith \& Curtis, 2003).

A investigação evidência que se quisermos promover o otimismo nos alunos implica que os professores apresentem vivências que suportem o desenvolvimento e a manutenção do otimismo (Boman, Furlong, Shochet, Lilles, \& Jones, 2009). Muitas vezes os professores pensam e dizem que são positivos e que utilizam técnicas positivas para controlar os comportamentos dos alunos, mas na realidade, os autorrelatos de positividade não estão em consonância com a observação dos professores em contexto de sala de aula (Jenson, Olympia, Farley \& Clark, 2004). De acordo com Korthagen $(2012,156)$, quando falamos da escola e dos professores " $A$ verdadeira mudança apenas terá lugar quando as pessoas estiverem dispostas a ampliar as suas zonas de conforto. As tensões no mundo de hoje mostram como isso pode ser crucial." É preciso compreender que a identidade do professor e a sua missão pessoal encontram-se relacionados com o seu comportamento profissional, e como diz Hamachek (1999, 209; cit. Korthagen, 2012, 156), "Conscientemente, ensinamos o que sabemos; inconscientemente, ensinamos o que somos", por isso, ensinamos também como florescemos e como se alcança a felicidade, pelo que devemos tomar consciência desta riqueza e estar preparados para o fazer. Mas, também acautelar quando não existe este potencial nos professores permitindo-lhes o desenvolvimento das suas competências de forma a que possam ensinar bem-estar. A educação positiva é uma opção viável e a considerar na escola, mas porquê ensinar o bem-estar? Como refere Seligman $(2012,95)$ "(...) o bem-estar devia ser ensinado nas escolas, porque é um antídoto para a crescente incidência da depressão, uma forma de aumentar a satisfação com a vida e uma ajuda para aperfeiçoar a aprendizagem e o pensamento criativo." Mas, é preciso tomar cuidado para que a educação positiva se torne uma parte fundamental da educação como um todo, e não simplesmente uma moda de curta duração (Slemp, Chin,Kern, Siokou, Loton, Oades, Vella-Brodrick, \& Waters, 2017). Existem estratégias e planos para atingir a felicidade, como por exemplo, a formação da mente para a felicidade, a atenção aos outros, gastar dinheiro com os outros para promover a felicidade e seguir o código para o bem-estar e felicidade. Neste sentido, uma educação positiva ao longo da vida pode ser uma ação a privilegiar e a implementar pelos agentes decisores e políticos, a qual será de bom grado acolhida e trabalhada pelos psicólogos na família, na escola, no trabalho e na comunidade.

\section{Referências}

Boman, P., Smith, C., \& Curtis, D. (2003). Effects of pessimism and explanatory style on the development of anger in children. School Psychology International, 24, 80-94.

Boman, P., Furlong, M., Shochet, I., Lillies, E., \& Jones, C. (2009). Optimism and the School Context. In R. Gilman, S. Huebner, M. Furlong (Eds.), The Handbook of Positive Psychology in Schools, (51-64). New York: Routledge.

Csikszentmihalyi, M. (1990). Flow: The psychology of optimal experience. New York: Harper \& Row.

Csikszentmihalyi, M. (2000). Happiness, flow, and economic equality. American Psychologist, 55(10), 1163-1164.http://dx.doi.org/10.1037/0003-066X.55.1 0.1163

Csikszentmihalyi, M. (2002). Fluir. Lisboa: Relógio D'Água, ISBN: 9789727086849

Goleman, D. (2001). Inteligência Emocional. Lisboa: Temas e Debates

Inglehart, R., Foa, R., Peterson, C. \& Welzel, C. (2007) Development, freedom, and rising happiness: a global perspective, Perspectives on Psychological Science, 3, 264-285.

Jenson, W., Olympia, D., Farley, M., \& Clark, E. (2004).

Positive psychology and externalizing students in a sea of negativity. Psychology in the School, 41(1), 67-79.

Korthagen, F. (2012). A prática, a teoria e a pessoa na formação de profesores. Educação, Sociedade \& Culturas, 36, 141-158

Lewinsohn, P., Rohde, P., Seeley, J. \& Fischer, S. (1993) Age-cohort changes in the lifetime occurrence of depression and other mental disorders, Journal of Abnormal Psychology,102, 110-120.

Martin,. P. (2006). Pessoas felizes, a natureza da felicidade e as suas origens na infância. Lisboa: Bizâncio.

Seligman, M. (2002). Authentic happiness: using the new positive psychology to realize your potential for lasting fulfillment. New York: Free Press

Seligman, M., Ernst, R., Gillhamc, J.Reivicha, K. \& Linkins, M. (2009). Positive education: positive psychology and classroom interventions. Oxford Review of Education. 35, 3, 293-311. ISSN 0305-4985, DOI: 10.1080/03054980902934563

Seligman, M. (2012). A vida que floresce- Um novo conceito visionário da felicidade e do bem-estar. Alfragide: Estrela Polar. ISBN:978-989-2068-1-7

Slemp,G.,Chin,T.,Kern,M.,Siokou,C.,Loton,D.,Oades, Vella-Brodrick, D. \& Waters, L. (2017). Positive Education in Australia: Practice, Measurement, and Future Directions. In Erica Frydenberg, Andrew J. Martin, Rebecca J. Collie (Eds.). Positive Education 
in Australia: Practice, Measurement, and Future Directions. 1, 101-122, ISBN: 978-981-10-3393-3; DOI:10.1007/978-981-10-3394-0 6

Veiga, F. (Cord.) (2013). Psicologia da Educação, Teoria, Investigação e Aplicação, Envolvimento dos Alunos na Escola. Lisboa: Climepsi. ISBN 978-972-796-337-9 